\title{
Upaya POLANTAS dalam Mengurangi Pelanggaran Lalu Lintas Siswa SMK Negeri 1 Ranah Ampek Hulu Tapan
}

\author{
Nadia Afrita, Henni Muchtar \\ Program Studi Pendidikan Pancasila dan Kewarganegaraan \\ Universitas Negeri Padang \\ E-mail: nadiaafrita1410@gmail.com
}

\section{ABSTRAK}

Upaya polisi lalu lintas untuk meningkatkan tertib lalu lintas bagi pengguna kendaraan bermotor sangatlah penting. Kegiatan tersebut bertujuan menciptakan ketertiban, kelancaran dan keselamatan dalam berlalu lintas salah satunya pada siswa SMK Negeri 1 Ranah Ampek Hulu Tapan yang sangat jarang menggunakan kelengkapan berkendaraan bermotor seperti penggunaan helm, kaca spion, dan selain itu juga siswa banyak yang menggunakan knalpot racing dan berboncengan tiga. Metode penelitian ini adalah kualitatif dengan pendekatan deskriptif. Data diperoleh dari data primer dan data sekunder. Teknik yang digunakan observasi, wawancara, dan studi dokumentasi. Hasil penelitian ini menunjukkan bahwa polisi lalu lintas telah melakukan upaya untuk meningkatkan tertib lalu lintas pada siswa SMK Negeri 1 Ranah Ampek Hulu Tapan dengan Pola preemtif berupa sosialisasi dan penyuluhan, pola represif dengan melakukan razia di sekolah, dan pola Preventif dengan melakukan patroli pada malam hari untuk meningkatkan tertib lalu lintas pada remaja tingkat siswa SMK/SMA, dan SMP. Dari tiga upaya yang telah dilakukan polisi lalu lintas pada siswa SMK N 1 Ranah Ampek Hulu Tapan dalam meningkatkan tertib lalu lintas masih belum maksimal karena ada beberapa kendala baik dari polisi itu sendiri, kurangnya personil polisi lalu lintas dan dari siswa SMK kurang merespon dari upaya yang dilakukan oleh polisi lalu lintas. Dimana respon siswa hanya berlangsung dalam beberapa hari kemudian kembali tidak mematuhi tertib dalam berlalu lintas.

Kata Kunci: tertib lalu lintas, pelanggaran lalu lintas, SMK Negeri 1 Ranah Ampek Hulu Tapan

\section{ABSTRACT}

Traffic police efforts are very important to improve traffic order for motor vehicle users in the State Vocational School Students 1 Ranah Ampek Hulu Tapan which aims to create order, smoothness and safety in traffic, because traffic order in students of State Vocational School 1 Ranah Ampek Hulu Tapan is very lacking in the use of motorized driving equipment such as the use of helmets, mirrors, and besides that many students also use exhaust resign and three-tricycle. This research method is qualitative with descriptive approach. Data obtained from primary data and secondary data. Techniques that involve observation, interviews, and documentation studies. The results of this study indicate that the traffic police have made efforts to improve traffic order in the students of State Vocational School 1 Ranah 
Ampek Hulu Tapan with Precative Patterns in the form of socialization and counseling, Repressive Patterns by conducting raids at schools, and Preventive Patterns by conducting night patrols to improve traffic order in adolescent level of vocational / high school and junior high school students. The three efforts that have been made by the police then others in the Ranah Ampek Hulu Tapan Vocational School students in improving traffic order are still not maximal because there are several obstacles both from the police themselves, the lack of traffic police personnel and from students of the State Vocational School 1 Ranah Ampek Hulu Tapan lack of response from the efforts made by the traffic police. Where the response of students only lasted a few days later returned did not obey order in traffic.

Keywords : orderly traffic, traffic violations, SMK Negeri 1 Ranah Ampek Hulu Tapan

This work is licensed under the Creative Commons Attribution-ShareAlike 4.0 International License. (2019 by author

\section{PENDAHULUAN}

Tertib berlalu lintas adalah keadaan berlalu lintas yang berlangsung secara teratur dan sesuai dengan hak dan kewajiban setiap pengguna jalan. Tertib berlalu lintas telah diatur dalam Undang-Undang No 22 Tahun 2009 tentang berlalu lintas dan angkutan jalan. Adanya aturan mengenai lalu lintas dan angkutan jalan berguna agar adanya pedoman dalam berlalu lintas sehingga terciptanya keselamatan, ketertiban, kelancaran dan keamanan dalam berlalu lintas. Hal ini sesuai dengan Pasal 106 dalam UndangUndang Lalu Lintas dan Angkutan Jalan No 22 Tahun 2009 yaitu "setiap orang yang menggunakan jalan wajib berprilaku tertib agar mencegah halhal yang mungkin dapat membahayakan keselamatan, kelancaran, maupun menimbulkan kerusakan jalan dalam berlalu lintas.

Hal ini disampaikan juga oleh Rahim (Yurselina: 2019) " tertib lalu lintas bertujuan untuk menciptakan keamanan, keselamatan, ketertiban, dan kelancaran lalu lintas. Berbagai upaya dilakukan oleh polisi lalu lintas seperti razia, memeriksa kelayakan kendaraan bermotor serta diskusidiskusi pada masyarakat dilakukan untuk menciptakan ketertiban dan kenyamanan serta keselamatan dalam berlalu lintas bagi para pengguna jalan.

Dalam mewujudkan ketertiban dalam berlalu lintas, Undang-Undang No 22 Tahun 2009 Tentang Lalu Lintas dan Angkutan Jalan telah jelas menjelaskan tata cara dalam berlalu lintas bagi pengguna jalan yang terdapat dalam Pasal 106 yaitu sebagai berikut: "setiap orang yang mengemudi kendaraan bermotor di jalan wajib mengemudikan kendaraannya dengan wajar dan penuh konsentrasi" (Pasal 106 ayat 1). Setiap orang yang mengemudikan kendaraan bermotor di jalan wajib mengutamakan keselamatan pejalan kaki dan pesepeda" (Pasal 106 ayat 2). Setiap orang yang mengemudi kendaraan bermotor di jalan wajib mematuhi ketentuan tentang persyaratan teknis dan laik jalan" (Pasal 106 ayat 3).

Setiap orang yang mengemudi sepeda motor dan penumpang sepeda motor wajib mengenakan helm yang memenuhi standar nasional 
Indonesia” (Pasal 106 ayat 8); “setiap orang yang mengemudikan sepeda motor tanpa kereta samping dilarang membawa penumpang lebih dari 1 (satu) orang" (Pasal 106 ayat 9)".

Undang-Undang Lalu Lintas No 22 Tahun 2009 juga mengatur perlengkapan yang harus dilengkapi oleh pengguna kendaraan bermotor. Aturan itu terdapat dalam Pasal 57 ayat 1 yang menyatakan bahwa setiap kendaraan bermotor yang dioperasikan di jalan wajib dilengkapi dengan perlengkapan kendaraan bermotor. Kemudian Pasal 57 ayat 2 menjelaskan bagi sepeda motor wajib menggunakan helm standar nasional. Pasal 285 ayat 1 lebih jelas mengatur perlengkapan yang harus di lengkapi oleh pengguna sepeda motor dan sanksinya jika dalam mengoperasikannya di jalan raya tidak mematuhinya seperti kaca spion, klakson, lampu utama, lampu rem, lampu penunjuk arah, alat pemantul cahaya, alat pengukur kecepatan, knalpot dan kedalaman alur ban. Jika setiap pengemudi yang tidak mematuhi aturan ini maka akan dipidana dengan pidana kurungan selama satu bulan atau denda sebanyak dua ratus lima puluh ribu rupiah.

Berdasarkan kelengkapan kendaraan bermotor yang telah diatur oleh Undang-Undang No 22 Tahun 2009 masih banyak siswa SMK Negeri 1 Ranah Ampek Hulu Tapan yang melanggar peraturan lalu lintas dalam penggunaan kelengkapan bermotor seperti penggunaan helm, kaca spion, knalpot standar, tidak memiliki SIM, membawa penumpang lebih dari satu, maupun membawa kendaraan dengan kecepatan tinggi. Selain itu juga menggunakan kendaraan yang tidak layak pakai karena banyak kerangka sepeda motor yang sudah dimodifikasi yang tidak sesuai dengan standar nasional. Hal ini sesuai dengan dijelaskan oleh penelitian Sadono (2016) bahwa pelanggaran lalu lintas terjadi karena cara pengendara yang tidak mematuhi peraturan lalu lintas. Kemudian keadaan ini di jelaskan oleh Emile Durkheim dalam Sadono (2016) perilaku seperti diatas disebut dengan anomie yaitu tidak adanya pegangan pada kaidah-kaidah sehingga menyebabkan keadaan tidak stabil.

Penelitian terkait dengan Upaya Polisi Lalu Lintas dalam mengurangi pelanggaran lalu lintas oleh pengguna kendaraan bermotor dilakukan oleh Rahim (2018) peran unit lantas dalam meningkatkan tertib lalu lintas yaitu dengan melakukan razia dengan memberikan tilang bagi pelanggar, melakukan sosialisasi kepada masyarakat, dan membuat ramburambu lalu lintas. Namun belum maksimal karena kekurangan anggota personil dan kurangnya sosialisasi kepada masyarakat serta kepedulian masyarakat akan tertib lalu lintas yang masih kurang. Hal ini sejalan dengan penelitian Yurserlina, A (2019) dalam menanggulangi pelanggaran lalu lintas oleh pelajar satuan lalu lintas Polres Bukittinggi melakukan pencegahan secara preventif dan represif dan hambatannya data dari kurangnya kesadaran hukum dan kepatuhan hukum di kalangan pelajar.

Penelitian yang sama juga pernah dilakukan oleh Barthos (2016) peran polisi lalu lintas dalam meningkatkan kesadaran lalu lintas yaitu dengan fungsi represif dan fungsi tindakan hukum. Kemudian 
melakukan tindakan preventif dengan memberikan pemahaman tentang UU No 22 Tahun 2009. Sedangkan kendala yang ditemukan dalam penelitian ini adalah kecenderungan masyarakat yang sengaja melakukan pelanggaran lalu lintas dan perilaku oknum penegak hukum lalu lintas yang moralnya kurang baik. Kemudian penelitian terkait dengan meningkatkan tertib lalu lintas pada siswa juga dilakukan oleh Hasibuan, J. P. (2015).

Penelitian ini melihat pada peran sekolah dalam meningkatkan kesadaran hukum berlalu lintas pada siswa yaitu dengan cara intrakurikuler yang ada dalam pelajaran PPKn dan BK dan kegiatan ekstrakurikuler dengan cara melakukan sosialisasi tentang lalu lintas yang bekerjasama dengan Dinas Perhubungan dan Kepolisian dalam pembuatan SIM di sekolah sehingga berdampak pada segi pengetahuan dan sikap siswa. Dalam penelitian Sarry, \& Widodo, H. (2014) berkaitan namun melihat pada upaya polisi lalu lintas dalam meningkatkan kedisiplinan lalu lintas pengendara bermotor, yaitu dengan melaksanakan program jalur kiri dan kendala dalam penelitian ini prilaku berkendara masyarakat, penata jalan dan rambu-rambu lalu lintas yang tidak memadai.

Polisi lalu lintas adalah kepolisian yang diberikan tugas pada bidang lalu lintas agar dapat meningkatkan keamanan, ketertiban, kelancaran dalam berlalu lintas. Polisi lalu lintas memiliki tugas pokok yang di atur dalam Peraturan Kepala Kepolisian Negara Republik Indonesia No 23 Tahun 2010 yaitu melaksanakan tugas Turjawali lalu lintas, memberikan pendidikan masyarakat lalu lintas, memberikan layanan registrasi dan identifikasi kendaraan bermotor dan pengemudi, melakukan penyidikan lalu lintas dan memberikan penegakan hukum lalu lintas.

Hal ini juga di atur dalam Undang-Undang No 22 Tahun 2009 yaitu dalam Pasal 12 menyatakan bahwa tugas kepolisian yaitu pengujian dan penerbitan SIM kendaraan bermotor, pelaksanaan registrasi dan identifikasi kendaraan bermotor, pengumpulan, pemantauan, pengelolaan, dan penyajian data lalu lintas dan angkutan jalan, pengelolaan pusat pengendalian sistem informasi dan komunikasi lalu lintas dan angkutan jalan, pengaturan, penjagaan, pengawalan, serta patroli lalu lintas. Patroli lalu lintas merupakan kegiatan ronda yang dilakukan pada ruas jalan untuk melakukan pengawasan pada arus lalu lintas dan aktifitas masyarakat pemakai jalan. Penegakan hukum meliputi penindakan pelanggaran dan penanganan kecelakaan lalu lintas, pendidikan berlalu lintas dan pelaksanaan manajemen dan rekayasa lalu lintas.

Penelitian ini akan memusatkan pada upaya polisi lalu lintas dalam meningkatkan tertib lalu lintas bagi pengguna kendaraan bermotor pada siswa SMK Negeri 1 Ranah Ampek Hulu Tapan. Berdasarkan wawancara yang dilakukan dengan polisi lalu lintas dan dengan pihak sekolah dan observasi pada kendaraan bermotor siswa SMK Negeri 1 Ranah Ampek Hulu Tapan. Terdapat beberapa masalah-masalah yang sering dilanggar dalam berjalan lintas oleh siswa SMK Negeri 1 Ranah Ampek Hulu Tapan yaitu a) kurangnya dalam 
penggunaan helm, penggunaan knalpot racing, kendaraan bermotor yang tidak dilengkapi kaca spion, tidak memiliki SIM, berboncengan melebihi kapasitas, tidak menyalakan lampu utama, kerangka motor yang sudah banyak dibuka sehingga seperti sepeda.

Berdasarkan masalah diatas menurut pihak polisi lalu lintas dan pihak sekolah telah melakukan kerjasama dalam meningkatkan tertib lalu lintas pada siswa SMK Negeri 1 Ranah Ampek Hulu Tapan yaitu dengan melakukan sosialisasi dan penyuluhan, razia di sekolah dan patroli pada malam hari. Sehingga terciptanya tertib lalu lintas pada siswa SMK Negeri 1 Ranah Ampek Hulu Tapan. Dalam hal ini peneliti berharap pihak sekolah dan polisi lalu lintas dapat membentuk polisi sekolah yang diambil dari siswa SMK itu sendiri sehingga pendekatan lebih mudah diterima oleh siswa SMK yang lain sehingga tertib lalu lintas pada siswa SMK Negeri 1 Ranah Ampek Hulu Tapan dapat lebih maksimal.

Tujuan penelitian ini adalah untuk mengetahui upaya polisi lalu lintas dalam meningkatkan tertib lalu lintas bagi pengguna kendaraan bermotor pada siswa SMK Negeri 1 Ranah Ampek Hulu Tapan. Penulis berharap upaya polisi lalu lintas dan pihak sekolah lebih ditingkatkan lagi dalam menjaga tertib lalu lintas pada generasi muda yaitu pada siswa SMK Negeri 1 Ranah Ampek Hulu sehingga di Tapan terciptanya keamanan, ketertiban, kelancaran dan keselamatan dalam berlalu lintas pada kalangan siswa. Manfaat penelitian ini diharapkan polisi lalu lintas dapat menciptakan upaya-upaya lebih menarik dalam meningkatkan tertib lalu lintas pada siswa atau masyarakat sehingga mudah diterima terutama untuk polisi lalu lintas di daerahdaerah sehingga tertib lalu lintas bukan hanya di kota-kota besar saja namun di daerah-daerah juga harus menaati peraturan lalu lintas seperti yang tercantum dalam UU No 22 Tahun 2009 Tentang Lalu Lintas dan Angkutan Jalan.

\section{METODE PENELITIAN}

Metode yang digunakan dalam penelitian ini adalah metode deskriptif kualitatif. Metode ini akan mendeskripsikan, mencatat, menganalisis upaya polisi lalu lintas dalam meningkatkan tertib lalu lintas bagi pengguna kendaraan bermotor. Informan dalam penelitian ini adalah Kapolsek Tapan, polisi lalu lintas di Tapan, Kepala sekolah dan wakil kepala sekolah SMK Negeri 1 Ranah Ampek Hulu Tapan, guru, siswa SMK Negeri 1 Ranah Ampek Hulu Tapan yang membawa kendaraan ke sekolah, wali murid. Penelitian dilakukan di SMK Negeri 1 Ranah Ampek Hulu Kecamatan Ranah Ampek Hulu, Kabupaten Pesisir Selatan. Dalam pengumpulan data penelitian ini menggunakan beberapa cara yaitu wawancara yang dilakukan berdasarkan pedoman wawancara, observasi dengan mengamati lokasi penelitian sekaligus melakukan wawancara dengan informan. Kemudian studi dokumentasi yang berupa rekaman dari hasil wawancara, kumpulan foto sebagai alat pendukung dalam penelitian ini.

Dalam menganalisis data peneliti menggunakan teknik analisis data menurut model Miles dan Huberman (Sugiyono:2012) yaitu pertama reduksi 
data merupakan merangkum, memilih hal pokok dari hasil wawancara yang dianggap penting dalam menjawab persoalan peneliti mengenai upaya polisi lalu lintas dalam meningkatkan tertib lalu lintas bagi pengguna kendaraan pada siswa SMK Negeri 1 Ranah Ampek Hulu Tapan. Kedua penyajian data setelah dirangkum hasil wawancara, observasi dan studi dokumentasi kemudian data disajikan dalam bentuk penjelasan teks sehingga mudah dipahami. Ketiga verifikasi data atau kesimpulan dari penyajian data untuk menjawab pertanyaan penelitian.

\section{HASIL DAN PEMBAHASAN}

Upaya polisi lalu lintas dalam meningkatkan tertib lalu lintas bagi pengguna kendaraan studi pada siswa SMK N I Ranah Ampek Hulu Tapan dapat dideskripsikan sebagai berikut:

\section{a. Pola preemtif}

Dalam meningkatkan tertib lalu lintas bagi pengguna kendaraan bermotor pada siswa, polisi lalu lintas melakukan sosialisasi dan penyuluhan berupa pemberian informasi mengenai pentingnya menggunakan kelengkapan bermotor seperti, helm, kaca spion, dan kelengkapan lainnya saat mengemudikan kendaraan bermotor. Hal ini sesuai dengan tugas polisi lalu lintas. Tugas polisi lalu lintas adalah menjalankan tugas polri di bidang lalu lintas meliputi segala usaha, pekerjaan dan kegiatan dalam pengendalian lalu lintas (Dedek Buana: 2017).
Pengendalian lalu lintas dilakukan untuk mencegah dan meniadakan segala bentuk gangguan serta ancaman agar terjamin keamanan, ketertiban, keselamatan dan kelancaran berlalu lintas di jalan umum dan tugas itu juga diatur dalam UU No 23 Tahun 2009 Tentang Lalu Lintas dan Angkutan Umum dalam Pasal 12 huruf G polisi lalu lintas juga berkewajiban memberikan pendidikan lalu lintas kepada masyarakat termasuk pada siswa. Jadi dengan itu polisi lalu lintas berperan penting dalam mengupayakan terjadinya keamanan, ketertiban dan kelancaran dalam berlalu lintas dan Pasal I Ayat 32 UU No 22 Tahun 2009 menjelaskan ketertiban lalu lintas dan angkutan jalan adalah suatu keadaan berlalu lintas yang berlangsung secara teratur sesuai dengan hak dan kewajiban setiap pengguna jalan.

Kegiatan sosialisasi dan penyuluhan yang dilakukan oleh polisi lalu lintas disebut sebagai pola preemtif yaitu dengan cara memberikan informasi kepada seluruh masyarakat. Kegiatan ini disebut juga sebagai "pendidikan lalu lintas kepada masyarakat yang merupakan usaha dalam membimbing, mengarahkan, mendidik masyarakat untuk dapat memahami ketentuan-ketentuan dalam peraturan lalu lintas (Barthos, 2018). Dalam hal ini penyuluhan dan himbauan yang dilakukan oleh polisi lalu lintas diberikan kepada siswa SMK Negeri 1 Ranah Ampek Hulu Tapan karena banyak siswa SMK 
Negeri 1 Ranah Ampek Hulu Tapan yang tidak mematuhi aturan lalu lintas dalam penggunaan kelengkapan bermotor seperti penggunaan helm, kaca spion, SIM, tidak menggunakan knalpot standar, berboncengan tiga dan kecepatan yang tinggi. Upaya polisi lalu lintas dalam meningkatkan tertib lalu lintas pada siswa SMK Negeri 1 Ranah Ampek Hulu Tapan dengan melakukan kerjasama dengan pihak sekolah dengan cara sosialisasi dan penyuluhan kepada siswa. Sosialisasi dan penyuluhan kepada siswa dilakukan sebanyak dua kali dalam satu bulan.

Kerjasama yang dilakukan oleh polisi lalu lintas dengan pihak sekolah sesuai dengan fungsi satuan lalu lintas dimana melakukan pembinaan pada masyarakat dengan melakukan kerjasama dalam berbagai sektor dalam hal ini bekerjasama dalam sektor pendidikan. Jadi sosialisasi dan penyuluhan yang dilakukan oleh polisi lalu lintas merupakan upaya yang dilakukan polisi lalu lintas di Tapan dalam meningkatkan tertib lalu lintas pada siswa SMK Negeri 1 Ranah Ampek Hulu Tapan yang masih kurang dalam penggunaan kelengkapan bermotor terutama dalam penggunaan helm, dan pengurangan penggunaan knalpot racing.

Sosialisasi dan penyuluhan dilakukan oleh polisi lalu lintas saat awal masuk siswa baru yaitu pada saat masa pengenalan lingkungan sekolah dan pada saat upacara bendera dimana pihak Polsek khususnya polisi lalu lintas diminta menjadi pembina upacara dalam hal itu polisi lalu lintas memberikan himbauan tentang pentingnya tertib dalam berlalu lintas. Kemudian penyuluhan dilakukan di dalam ruangan sekitar satu sampai dua jam dimana dalam penyuluhan ini polisi lalu lintas mencontohkan langsung pentingnya penggunaan helm agar jika terjadi kecelakaan tidak mengakibatkan benturan yang keras ke kepala. Kegiatan ini juga diberikan kesempatan kepada siswa untuk mempraktekkan. Sosialisasi dan penyuluhan sebagai upaya dalam meningkatkan tertib lalu lintas pada siswa SMK Negeri 1 Ranah Ampek Hulu Tapan yang merupakan pola preemtif dikreasikan oleh polisi lalu lintas agar menarik minat siswa untuk mendengarkannya dengan cara memberi hadiah kepada siswa yang lengkap dalam kelengkapan berkendaraan.

Jadi dapat disimpulkan pola preemtif merupakan salah satu upaya yang digunakan oleh polisi lalu lintas dalam meningkatkan tertib lalu lintas bagi pengguna kendaraan bermotor pada siswa SMK Negeri 1 Ranah Ampek Hulu Tapan. Adanya upaya yang dilakukan oleh polisi lalu lintas dalam meningkatkan tertib lalu lintas kepada siswa SMK diharapkan dapat menciptakan ketertiban lalu lintas dan angkutan jalan sesuai dengan Pasal I Ayat 32 UU No 22 Tahun 2009 yang berbunyi "Ketertiban lalu lintas dan 
angkutan jalan adalah suatu keadaan berlalu lintas yang berlangsung secara teratur sesuai dengan hak dan kewajiban setiap pengguna jalan".

\section{b. Pola Represif}

Razia merupakan upaya yang dilakukan oleh polisi lalu lintas dalam meningkatkan tertib lalu lintas bagi pengguna kendaraan bermotor. Sesuai dengan tugas polisi lalu lintas yang terdapat dalam Undang-undang No 22 Tahun 2009 dalam Pasal 12 huruf F yang berbunyi "Penegakan hukum meliputi penindakan pelanggaran dan penanganan kecelakaan lalu lintas". Razia yang dilakukan oleh polisi lalu lintas berupa teguran dan penindakan yang diberikan pada siswa yang tidak tertib dalam berlalu lintas. Tertib lalu lintas pada siswa SMK Negeri 1 Ranah Ampek Hulu lebih pada penggunaan helm, dan mengurangi penggunaan knalpot racing oleh siswa yang merupakan kesepakatan yang telah disepakati oleh pihak sekolah dengan pihak Polsek Tapan dalam hal ini dengan polisi lalu lintas. Jika kedapatan melanggar kesepakatan yang telah ditentukan maka siswa tersebut diberikan teguran dan kemudian baru ditindak dengan membuat surat perjanjian dengan orang tua siswa.

Razia termasuk ada pola represif yaitu penegakan hukum yang diberikan melalui teguran maupun tilang kepada setiap pelanggar lalu lintas. Hal ini disebut dengan kegiatan "pencegahan hukum lalu lintas yaitu dengan cara represif yang berupa penindakan terhadap pelanggaran lalu lintas" (Barthos: 2018). Maka itulah yang dilakukan oleh polisi lalu lintas di Tapan kepada siswa SMK Negeri 1 Ranah Ampek Hulu Tapan dalam meningkatkan tertib lalu lintas pada siswa berupa teguran namun bukan dalam bentuk tilang.

Razia yang dilakukan oleh polisi lalu lintas yang bekerjasama dengan pihak sekolah belum efektif karena masih belum maksimal perubahan yang terjadi pada siswa dalam tertib lalu lintas terutama penggunaan helm, dan pengurangan pemakaian knalpot racing. Tertib yang terjadi di kalangan siswa hanya terjadi beberapa hari setelah dilakukan razia kemudian kembali tidak menggunakan kelengkapan bermotor saat membawa kendaraan bermotor ke sekolah seperti penggunaan helm, kaca spion, dan tidak memakai knalpot standar.

Jadi dapat disimpulkan dalam meningkatkan tertib lalu lintas bagi pengguna kendaraan bermotor pada siswa SMK Negeri 1 Ranah Ampek Hulu Tapan polisi lalu lintas bekerjasama dengan pihak sekolah dengan melakukan razia terhadap kendaraan siswa yang tidak lengkap terutama penggunaan helm, dan knalpot standar. Razia yang dilakukan oleh pihak polisi dan pihak sekolah terhadap siswa SMK Negeri 1 Ranah Ampek Hulu Tapan masih belum maksimal dalam mengupayakan tertib lalu lintas pada siswa dalam 
penggunaan helm, kaca spion dan pengurangan pemakaian knalpot racing pada siswa SMK Negeri 1 Ranah Ampek Hulu Tapan.

\section{c. Pola Preventif}

Patroli pada malam hari merupakan upaya yang dilakukan oleh Polisi Lalu Lintas dalam meningkatkan tertib lalu lintas pada siswa SMK Negeri 1 Ranah Ampek Hulu Tapan. Patroli malam dilakukan oleh Polisi Lalu Lintas terutama pada malam minggu karena pada malam minggu banyak pelajar yang berpotensi melakukan balap liar dan ugal-ugalan di jalan. Pagi hari polisi lalu lintas juga melakukan penjagaan di sekitar area simpang Tapan untuk mengatur arus lalu lintas. Menurut Undang-Undang No 22 Tahun 2009 pada Pasal 12, dijelaskan bahwa "Patroli lalu lintas merupakan kegiatan ronda yang dilakukan pada ruas jalan untuk melakukan pengawasan pada arus lalu lintas dan aktifitas masyarakat pemakai jalan". Patroli yang dilakukan oleh polisi lalu lintas merupakan upaya meningkatkan tertib lalu lintas pada siswa termasuk masyarakat agar tidak membawa kendaraan bermotor dengan kecepatan yang tinggi dan mematuhi aturan dalam penggunaan helm saat membawa kendaraan bermotor.

Jadi tertib lalu lintas yang dilakukan oleh polisi lalu lintas dengan cara melakukan patroli di jalan terutama pada malam minggu telah memberi dampak berkurangnya aksi balap liar dan ugal-ugalan dalam membawa kendaraan pada remaja tingkat SMP, SMA/SMK, namun belum pada penggunaan kelengkapan bermotor seperti helm, kaca spion, SIM, dan lain sebagiannya. Patroli yang dilakukan oleh Polisi Lalu Lintas seperti dijelaskan diatas merupakan pola preventif dimana personil Polisi diatur untuk melakukan patroli pada tempat dan waktu rawan akan melanggar lalu lintas. Pola Preventif ini disebut juga "tugas Polisi dalam pengaturan dan penjagaan dengan melakukan patroli lalu lintas" (Barthos, 2018).

Kendala-kendala yang dihadapi polisi lalu lintas dalam meningkatkan tertib lalu lintas bagi pengguna kendaraan bermotor

\section{Kurangnya Personil Polisi Lalu Lintas}

Kendala yang dihadapi oleh Polisi Lalu Lintas dalam meningkatkan tertib lalu lintas pada siswa SMK Negeri 1 Ranah Ampek Hulu Tapan adalah berasal dari Polisi Lalu Lintas sendiri karena kurangnya personil polisi lalu lintas. Kurangnya personil dari polisi lalu lintas yang ada di Polsek Tapan mengakibatkan polisi lalu lintas di Tapan tidak bisa memberikan upaya yang maksimal dalam meningkatkan tertib lalu lintas pada siswa SMK Negeri 1 Ranah Ampek Hulu Tapan. Hal ini didukung 
dengan hasil penelitian dalam artikel (Yuliani dan Kristina, 2015) “dalam sebuah organisasi atau instansi hal yang sangat mendasar adalah sumber daya manusia karena apabila sumber daya manusia yang berkerja tidak sebanding dengan jumlah pekerjaan yang dikerjakannya maka akan memungkinkan pekerjaan yang dikerjakan tidak maksimal atau kurang berhasil.

Kurangnya personil polisi lalu lintas di Tapan mengakibatkan setiap bidang Kanit saling membantu sama lain dalam menjalankan tugasnya masing-masing. Sehingga dalam menjalankan tugasnya Kanit Lantas dibantu oleh personil Polisi lainnya dalam melakukan sosialisasi dan penyuluhan ke sekolah SMK Negeri 1 Ranah Ampek Hulu Tapan. Begitupun dalam melakukan razia ke sekolah Kanit Lantas akan dibantu oleh rekannya tiga sampai lima orang membantunya ke sekolah untuk melakukan razia. Siswa yang kedapatan membawa kendaraan bermotor ke sekolah tidak menggunakan helm, kaca spion, dan tidak memakai knalpot standar (knalpot racing) maka siswa tersebut akan dikumpulkan oleh pihak polisi lalu lintas dan pihak sekolah untuk diberi arahan, dan membuat surat perjanjian, begitupun dalam patroli Kanit Lantas dibantu oleh rekannya untuk melakukan patroli pada malam hari terutama di tempat yang rawan terjadi kebut-kebutan atau kecepatan yang tinggi maupun tempat yang rawan untuk dilakukan sebagai tempat balap liar oleh remaja.

\section{Kurangnya Respon Siswa}

Respon siswa juga menjadi faktor atau kendala-kendala yang dihadapi oleh polisi lalu lintas dalam meningkatkan tertib lalu lintas. Pada saat sosialisasi dan penyuluhan yang dilakukan polisi lalu lintas pada siswa SMK Negeri 1 Ranah Ampek Hulu Tapan terdapat sebagian siswa yang tidak memperhatikan apa yang disampaikan atau himbauan yang diberikan oleh polisi lalu lintas saat melakukan penyuluhan dan sosialisasi. Hal inilah yang menyebabkan tertib lalu lintas kurang tercapai di SMK Negeri 1 Ranah Ampek Hulu Tapan. Namun meskipun demikian juga terdapat perubahan dalam berlalu lintas pada siswa dalam membawa kendaraan bermotor yaitu dalam penggunaan knalpot racing, pemakaian kaca spion dan penggunaan helm beberapa siswa sudah ada yang mematuhi meskipun belum maksimal.

Kurang maksimalnya penggunaan kelengkapan bermotor pada siswa SMK Negeri 1 Ranah Ampek Hulu Tapan karena belum membudayanya tertib lalu lintas pada masyarakat di daerah-daerah. Hal ini tentu saja berbeda dengan di kota-kota besar yang tertib lalu lintas sudah menjadi budaya bagi masyarakatnya. Sehingga membuat masyarakat maupun siswa wajib mematuhi aturan lalu lintas dalam penggunaan 
kelengkapan bermotor seperti yang disebut dalam UU No 22 Tahun 2009 dalam Pasal 58 dan Pasal 57 ayat 1 dan ayat 2 yang berbunyi sebagai berikut: "Setiap kendaraan bermotor yang dioperasikan di jalan dilarang memasang perlengkapan yang dapat mengganggu keselamatan berlalu lintas (Pasal 58)", kemudian pada Pasal 57 ayat "Setiap kendaraan bermotor yang dioperasikan dijalan wajib dilengkapi dengan perlengkapan kendaraan bermotor, "perlengkapan sebagaimana yang dimaksud ayat (1) bagi sepeda motor berupa helm standar nasional indonesia (Pasal 57 ayat 2)

Kemudia persyaratan teknis dalam menggunakan kendaraan bermotor yang diatur dalam UU No 22 Tahun 2009 Pasal 106 ayat 3 dan lebih jelas diatur dalam Pasal 285 ayat 1 perlengkapan yang perlu dilengkapi saat mengendarai kendaraan bermotor meliputi kaca spion, klakson, lampu utama, lampu rem, lampu penunjuk arah, alat pemantul cahaya, alat pengukur kecepatan, knalpot, dan kedalaman alur ban sehingga apabila melanggar akan di kenakan saksi pidana kurungan paling lama satu bulan penjara atau denda sebanyak RP 250.000.00 (Dua Ratus Lima Puluh Ribu Rupiah).

\section{SIMPULAN}

Upaya polisi lalu lintas dalam meningkatkan tertib lalu lintas bagi pengguna kendaraan bermotor terutama pada siswa tingkat SMP,
SMA dan SMK sangat penting dilakukan untuk meningkatkan tertib lalu lintas pada siswa sehingga tercipta keamanan, keselamatan, ketertiban dan kelancaran dalam berlalu lintas. Adapun upaya yang dilakukan oleh polisi lalu lintas bersama dengan pihak sekolah dalam meningkatkan tertib lalu lintas pada siswa SMK Negeri 1 Ranah Ampek Hulu Tapan adalah dengan Pola preemtif yaitu sosialisasi dan penyuluhan, pola represif melakukan razia dan pola preventif melakukan patroli pada malam hari.

Sedangkan kendala-kendala yang dihadapi oleh polisi lalu lintas dalam meningkatkan tertib lalu lintas pada siswa SMK Negeri 1 Ranah Ampek Hulu Tapan adalah pertama dari pihak polisi sendiri adalah kekurangan personil polisi lalu lintas. Sedangkan kendala eksternal adalah kurangnya respon siswa terhadap sosialisasi dan penyuluhan, razia dan patroli yang dilakukan oleh polisi lalu lintas sehingga perubahan yang terjadi pada siswa dalam tertib berlalu lintas hanya beberapa siswa sehingga upaya yang dilakukan oleh polisi lalu lintas di Tapan dalam meningkatkan tertib lalu lintas pada siswa SMK Negeri 1 Ranah Ampek Hulu Tapan masih kurang atau belum maksimal.

\section{DAFTAR PUSTAKA}

Barthos, M. (2018). Peranan Polisi Lalu Lintas Dalam Meningkatkan Kesadaran Hukum Pengendara Sepeda Motor Di Wilayah Polres Jakarta Pusat Berdasarkan Undang-Undang Nomor 22 Tahun 2009 Tentang Lalu Lintas Dan Angkutan Jalan. Lex Librum: Jurnal Ilmu Hukum, 4(2). 
Dedek Buana. 2017. "Tugas Pokok, Fungsi Dan Peran Polisi Lalu Lintas (Polantas)". Artikelddk.Com 7 Juli 2017.

Hasibuan, J. P. (2015). Peran Sekolah Dalam Meningkatkan Kesadaran Hukum Berlalu Lintas Siswa Sma Negeri 3 Cirebon (Doctoral Dissertation, Universitas Negeri Semarang).

Maleong, Lexy, J. 2012. Metodelogi Penelitian Kualitatif Edisi Revisi. Pt Remaja Rosdakarya. Bandung.

Noor, Juliansyah. 2015. Metodelogi Penelitian. Prenanda Media Group. Jakarta.

Peratutan Kepolisian Negara Republik Indonesia No 23 Tahun 2010.

Rahim, F. (2018). Peranan Unit lantas Polsek Muara Jawa Dalam Meningkatkan Ketertiban Berlalu Lintas Pada Masyarakat Kecamatan Muara Jawa Kabupaten Kutai Kartanegara.

Sadono, S. (2018). Budaya Tertib Berlalu-Lintas: Kajian Fenomenologis Atas Masyarakat Pengendara Sepeda Motor Di Kota Bandung. Lontar: Jurnal Ilmu Komunikasi, 3(3).

Sarry, Y. P., \& Widodo, H. (2014). Upaya Polisi Lalu Lintas Dalam Meningkatkan Kedisiplinan Berlalu Lintas Pengendara Bermotor (Studi Deskriptif Terhadap Program Kanalisasi Lajur Kiri Pada Satlantas Polrestabes Surabaya). Kajian Moral Dan Kewarganegaraan, 2(2), 564-578.

Standar Operasional Prosedur. Buku Saku Satlantas Sumbar. Sumatera Barat.
Sugiyono. 2012. Metode Penelitian Kuantitatif, Kualitatif Dan R\&D. Alfabet Cv. Bandung. Undang-Undang No 22 Tahun 2009 Tentang Lalu Lintas Dan Angkutan Jalan.

Yuliani, F., \& Kristian, T. (2015). Pengawasan Tertib Lalu Lintas Oleh Satlantas Kota Pekanbaru (Studi Kasus Jalan Sudirman). Jurnal Online Mahasiswa Fakultas Ilmu Sosial Dan Ilmu Politik Universitas Riau, 2(1). 